\title{
Investigating the Motivations and Constraints of Chinese Peer-to-Peer
}

\section{Accommodation Hosts}

\section{Author Biographies}

ShiNa Li (Ph.D.) is a Professor in the School of Tourism Management at Sun Yat-sen University. Her current research interests lie in tourism economics, sustainable development, poverty reduction and tourism, tourist behavior and events studies.

Lawrence Hoc Nang Fong (Ph.D.) is an Associate Professor in the Faculty of Business Administration at the University of Macau. His research focuses on social media marketing, online comment research, online consumer behavior, cognitive bias in gambling activities, tourism and gambling influence, and tourists' behavior.

Carol Xiaoyue Zhang (Ph.D.) is an Assistant Professor in the Nottingham University Business School of University of Nottingham. Her research is primarily focused on social-political changes, with interests in examining how those changes impacts on social and self-identities in the context of international tourism.

Mengxin Chen is a master student in Sun Yat-sen University. Her research interests include tourism economics and tourism space analysis. 


\begin{abstract}
Purpose - This research aims to identify peer-to-peer (P2P) accommodation hosts' perceived motivations and constraints, to examine the prediction of the motivation and constraint factors on hosts' intention to continue business based on hosts' attitudes, and to explore the moderating role of business scale.
\end{abstract}

Design/methodology/approach - A scale for hosts' perceived motivators and constraints was developed. Mixed methods were used to develop and analyse a conceptual framework for demonstrating how constraints and motivations influence hosts' behavioural intentions. Findings from interviews with hosts interpretatively supported the survey results.

Findings - Chinese hosts' perceived constraints and motivators are identified and explained. The survey results indicate that constraints lower intention to continue one's business and motivators heightens it. Motivators have a higher effect on attitudes and intentions than constraints do. Business scale was confirmed as a moderator in the constraint - attitude link but not in the motivator-attitude relationship.

Practical implications - This paper offers policy implications for governments, online platforms and hosts in terms of establishing incentives and solving problems so that Chinese hosts can sustainably operate their businesses.

Originality/value - This paper identifies constraints and motivators and develops a measurement scale for both simultaneously, which provides a holistic explanation of hosts' attitude and behavioural intention. It also reveals the moderating role of business scale. In investigating the thoughts of existing hosts operating on global and local platforms in China, this paper complements the literature, which mainly focuses on the Western context and a single global platform.

Keywords: P2P accommodation, hosts, motivations, constraints, continuance intention, business scale

Paper type: Research paper 


\section{Introduction}

The sharing economy has grown rapidly over the last decade, mainly due to the recognition of shared values and improvements in technology (OECD, 2016). The global revenues generated by the sharing economy, including hospitality, dining, car sharing, finance, staffing, and music and video streaming, are estimated to reach around US $\$ 335$ billion by 2025 (PwC, 2015). The sharing economy is based on digital platforms that share underused assets (Prayag and Ozanne, 2018). The tourism and hospitality sector is a dominant participant in and contributor to the sharing economy due to peer-to-peer (P2P) accommodation (Cheng and Edwards, 2019). After one of the earliest P2P accommodation platforms, Airbnb, was launched in 2007, the P2P accommodation business rapidly gained popularity among guests globally (Guttentag, 2015; Tham, 2016).

The sharing economy highlights the value of sharing, and its business activities heavily rely on interactions between hosts and guests. The boom in the P2P industry largely depends on the diversity of host offerings, and the platforms are merely the intermedium. These factors highlight the overlooked importance of hosts in the sharing economy. Compared to P2P accommodation consumers, who have been extensively evaluated in the literature (Karlsson and Dolnicar 2016; Moon et al. 2019), hosts' attitudes and behaviours have received little attention (Stors and Kagermeier, 2017). The few studies that have examined motivations and constraints have either focused on income and social interactions as motivations (Benoit et al. 2017; Farmaki, 2019; Farmaki and Stergiou, 2019; Karlsson and Dolnicar, 2016) or on perceived risks as constraints (Alraeeini et al., 2019; Malazizi et al., 2018). In this type of business, constraints and motivations often co-exist. 
The majority of the extant research has emphasised motivation factors and neglected the constraint factors that hosts encounter. These studies have attached importance only to the growth of the sharing-economy market, resulting in a lack of investigation into conflicts with other stakeholders, such as other residents and platforms, and the challenges posed by government regulations regarding safety, quality and hygiene. Thus, there is a gap in the literature concerning how such factors shape hosts' intentions to continue running their P2P accommodation businesses. Previous studies were conducted during the early stages of the P2P sharing-accommodation industry, when it was undergoing dramatic growth. The sharing model has now entered its second decade, during which a crisis has arisen, requiring the exploration of emerging issues. This study identifies and examines the constraints and motivators in a single model to provide a holistic, robust explanation of hosts' attitudes and behavioural intentions. This study also explores whether the relationships of constraint—attitude and motivatorattitude are contingent on business scale (single versus multiple properties). The implications of these findings can be suggested to hosts operating at different scales.

This research aims to identify hosts' perceived motivations and constraints, develop a measurement scale, and validate the predictive power of motivators and constraints on overall attitudes and behavioural intentions regarding future operation. Prior studies have mostly focused on Western countries and Airbnb, the implications of which may not be generalisable to Asian countries where local platforms have proved more popular than Airbnb. The present research focuses on the Chinese market and offers policy implications for relevant government departments and online platforms for establishing incentives and solving problems so that hosts can operate sustainable businesses. 
This study makes four contributions. First, it enriches understanding of the sharing economy by identifying the motivations and constraints perceived by service hosts operating $\mathrm{P} 2 \mathrm{P}$ accommodation and by developing a measurement scale. It contributes to the formation of a holistic picture of the sharing economy by complementing previous studies, which mainly focused on motivators. Second, the understanding of P2P accommodation management and experience has been restricted by the overwhelming focus on the Western context. Empirical evidence drawn from Chinese hosts provides implications that are relevant for Chinese destination management. Third, it demonstrates the power of various motivations and constraints in explaining business owners' continuance intention, whereas the literature has tended to examine the intention to join the industry. Fourth, previous research has focused on the predictors of hosts' attitudes towards and intentions to operate $\mathrm{P} 2 \mathrm{P}$ accommodation. Less is known about moderating factors. This study explores business scale as a boundary condition that differentiates constraint-attitude and motivator-attitude relationships.

\section{Literature review}

\subsection{Research on P2P accommodation hosts}

The satisfaction level and perceptions of the supply side of the sharing economy are believed to be as crucial as the demand side in influencing the sustainable development of this business (Dolnicar and Talebi, 2020). Many studies have focused on the demographic characteristics of hosts (e.g., profile photos, names and gender on online platforms) and their non-demographic attributes to examine how such factors affect hosts' business performance (Ert and Fleischer, 2019; Xie et al., 2017). 
The literature has explored hosts' attitudes towards platforms and guests, and some studies have examined hosts' behavioural intentions in relation to accepting/denying bookings and disclosing information. Wang et al. (2019) assessed the antecedents and consequences of hosts' trust in Airbnb and found that technical antecedents, including the quality of the system, service and information, had the strongest impact on hosts' trust in the platform. Karlsson et al. (2017) examined the factors influencing hosts' decision to accept or deny a booking. Their findings showed that hosts decide to accept a booking request based on age, guest self-assessment, length of booking, trip motivation, travel party, number of people in the profile picture and availability of the profile picture. Several studies have evaluated hosts' and guests' perceptions and behaviours, many of which have focused on the interactions between the two key stakeholders. Moon et al. (2019) found that hosts perceived fewer positive overall interactions and appeared to have a lower level of encounter satisfaction and behavioural intention compared with guests.

Airbnb and Couchsurfing are well-known P2P accommodation businesses (Prayag and Ozanne, 2018). Many studies on the sharing economy have been conducted in the context of Western countries and focused on mainstream online platforms, particularly Airbnb (Dolnicar, 2019), at the expense of diversity in the knowledge construction of the sharing economy. With the swift growth of P2P accommodation supply and demand in the Asian market and the launch of diversified local platforms, it is crucial to examine the operations of $\mathrm{P} 2 \mathrm{P}$ accommodation in Asia. Studies on Asian countries and non-Western platforms are limited, perhaps due to restrictions on data accessibility. The current research enriches the literature by collecting data in China on hosts' perceived motivations for and constraints on using Airbnb as well as local platforms. 


\subsection{Motivations and constraints of P2P accommodation hosts}

Although the importance of research on the hosts of P2P accommodation has been recognised (Prayag and Ozanne, 2018), research remains limited on the motivation and constraint factors influencing hosts' accommodation sharing (Wang et al., 2019). Service providers in the sharing economy run businesses based on different motivations and constraints (Böcker and Meelen, 2017). Karlsson and Dolnicar (2016) summarised three categories of motives: 1) income, which includes paying bills, making money and affording luxuries; 2) social interaction, which means meeting and interacting with guests from various backgrounds; and 3) sharing, which mainly refers to the sharing of space, although several respondents mentioned the sharing of joy. Among the three categories, economic reasons and social interaction have been identified as predominant drivers (e.g., Alrawadieh and Alrawadieh, 2018; Benoit et al., 2017; Farmaki, 2019; Farmaki and Stergiou, 2019). From their interviews with Airbnb hosts and guests, Farmaki and Stergiou (2019) learned that reducing loneliness was a key driver for hosts and guests to participate in a sharing business. Moreover, Benoit et al. (2017) captured entrepreneurial freedom, including the flexible offering and individualization of service as an important motivator for service providers and confirmed the positive role of electronic sharing systems. Based on Airbnb host data collected in Dubai, Alraeeini et al. (2019) discovered the low costs and high value linked to accommodation sharing and having a user-friendly, highly informative accommodation-sharing system as the main drivers of accommodation sharing. Sustainable and environmental considerations, such as sharing energy and water resources, are also important reasons for participating in the sharing economy (Hamari et al., 2015). These findings may reflect that the fundamental value of this business model is to share. 
The main constraint identified in the literature is risk. Malazizi et al. (2018) revealed that two types of risk, financial and safety/security, negatively affect Airbnb hosts' satisfaction and behavioural intentions, along with political risk. Farmaki (2019) pointed out that female hosts may face an increased risk to their safety. This assumption could be based on Airbnb's 'guestfirst approach', which restricts females from rejecting or cancelling bookings about which they may feel uncomfortable. Apart from risks, limited knowledge about platforms and underdeveloped legislation have also constrained hosts (Alraeeini et al., 2019; Malazizi et al., 2018). Alraeeini et al. (2019) showed that limited understanding of the use of new platforms and insufficient or underdeveloped legislation generated doubts over service quality and the benefits/losses of the business. Stiff competition was found to be another key challenge (Alrawadieh and Alrawadieh, 2018).

Research on the motivation and constraint factors of hosts has been scattered. Although Mahadevan (2019) examined motivators and barriers for hosts, she captured perceptions of guests as would-be hosts rather than existing hosts. The findings from that study indicate that a sharing philosophy is a dominant motive. In contrast, opportunity costs, such as the time spent on the property, and potential regulations, such as taxation and registration, are insignificantly associated with the intention to become a host. Mahadevan (2019) offered several insights into the influencing factors that attract existing guests to become hosts. However, in collecting guests' viewpoints, the study could not comprehensively identify the motivations and constraints of existing hosts to continue operating in the sharing business.

Studies that systematically analyse how hosts' motivators and constraints affect hosts' continuance intention are non-existent. The present study holistically evaluates hosts' motivation factors ('motivators' in the hypotheses) and constraint factors ('constraints' in the hypotheses). 
To validate the predictive power of the identified motivators and constraints, this study follows previous studies (Amaro et al., 2019; Huang and Hsu, 2009; So et al., 2018) by investigating their predictive relationships with hosts' attitudes towards $\mathrm{P} 2 \mathrm{P}$ accommodation business ('attitude' in the hypotheses) and behavioural intention to continue their P2P accommodation business ('intention' in the hypotheses). The theory of planned behaviour (TBP) can be used to examine behavioral intention, which can predict someone's actual behavior (Ajzen 1991). When TPB is applied to evaluating tourism and hospitality cases, it is found that motivators can largely explain variation of attitude and then behavioral intention (Huang and Hsu 2009). TPB has been applied to examining determinants of guests' intention to use Airbnb (So, Oh, and Min 2018). The negative (positive) effect of constraints (motivators) on behavioural intention will require the presence of an attitude as the explanatory variable (i.e., mediator). Specifically, constraints will lead to negative attitude towards continuance of $\mathrm{P} 2 \mathrm{P}$ accommodation business and then intention to exit the market, whereas motivators will lead to positive attitude towards continuance of $\mathrm{P} 2 \mathrm{P}$ accommodation business and then intention to stay in the market. Thus, the following hypotheses have been formulated.

H1: Constraints are negatively associated with attitude.

H2: Attitude mediates the negative relationship between the constraints and intention.

H3: Motivators are positively associated with attitude.

H4: Attitude mediates the positive relationship between the motivators and intention. 


\subsection{Business scale as a moderator}

Although research about $\mathrm{P} 2 \mathrm{P}$ accommodation has been well-documented in the literature, studies concerning hosts' attitudes towards and intentions to operate such businesses tend to focus on predicting factors (Mahadevan, 2019; Malazizi et al., 2018; Xie et al., 2017). Less is known about the factors that moderate the predicting effects. Understanding the significant moderator can help practitioners effectively act on research implications. To fill the gap in the literature, we propose that business scale, in the form of single versus multiple properties, is a moderator.

This proposition is grounded in the size-survival relationship of organisations, which suggests that a large organisation has advantages in business continuance (Bercovitz and Mitchell, 2007). Compared with small competitors, a large business generally has advantages in terms of accessing and allocating resources (Kaul, 2012), maximising operation efficiency (Halkos and Tzeremes, 2007), bargaining power when dealing with external parties (e.g., suppliers; Tyagi, 2001), and innovativeness (Zaridis et al., 2020). Given its advantages, a large business should be more capable of addressing the constraints imposed by an environment. However, motivators are internalised in people (Pritchard et al., 2009) and affect attitudes, which are also internalised; thus, they should be less susceptible to environmental factors (e.g., business scale). Consistent with this argument, prior study reported that entrepreneurs' motivation is primarily driven by the psychological benefits gained from operating the business (for examples independence, freedom, job satisfaction, and others) (Alstete, 2008). In sum, the motivator effect on attitude towards business continuance is unlikely to vary with business scale. By contrast, the attitude of a host is more likely to be affected by the constraints if the host operates a single property (i.e., small scale) than if the host operates multiple properties (i.e., large scale). It is hypothesised that: 
H5: Business scale moderates the negative relationship between the constraints and attitude, but it does not moderate the positive relationship between the motivators and attitude.

H5a: The negative relationship between constraints and attitude is significant for small-scale hosts (with a single property) but not for large-scale hosts (with multiple properties).

$H 5 b$ : The positive relationship between motivators and attitude is not contingent on business scale.

Figure 1 illustrates the hypotheses in a conceptual framework.

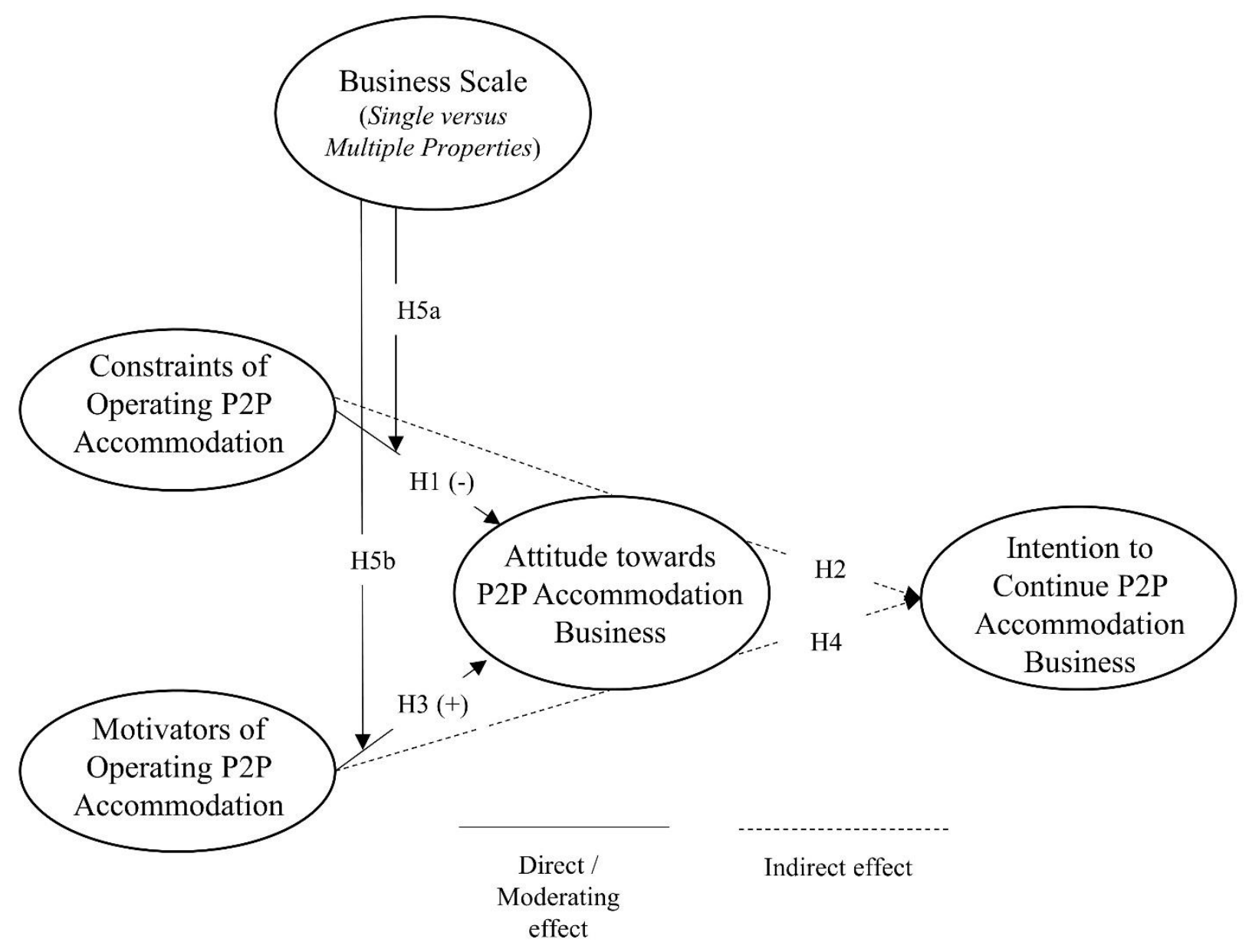

Figure 1. Conceptual framework 


\section{Research design}

We adopted a mixed-methods approach to conduct two studies, Study 1 and Study 2 (Creswell et al., 2003). In Study 1, a qualitative phase was followed by a quantitative phase. The qualitative phase was designed to supplement the inconsistent and Western-centric results of previous research and to identify hosts' motivations and constraints, which could then be tested to provide a relevant and useful scale. The quantitative phase involved the development and analysis of a conceptual framework to demonstrate how constraints and motivations influence P2P accommodation hosts' behavioural intentions. Study 2 included further explanatory qualitative research. The unique nature of Chinese P2P accommodation hosts necessitated further exploration of the model built in Study 1 . The qualitative data were additionally investigated to provide new insights that were drawn to support and explain some key findings of the quantitative research.

\subsection{Study 1: Methods and findings}

We used both qualitative and quantitative methods to develop a scale for Chinese hosts' motivators and constraints, following Churchill's (1979) scale development process. The items were generated based on qualitative data collected from in-depth interviews with hosts and a review of the literature (e.g., Liu and Mattila, 2017; So et al., 2018). We interviewed 20 hosts to provide rich information between June and July 2019. Themes were derived from the data (an inductive approach) based on the meaning captured in the interviews and existing literature (a deductive approach). The process identified 35 constraint items and 22 motivator items (see 
Table 1). The reliability and validity of these items were assessed using the questionnaire survey approach. In particular, the measurement model was tested. As discussed in the section entitled 'Motivations and constraints of P2P accommodation hosts', the predicting power of motivators and constraints was validated through an examination of their relationships with attitude and intention and the testing of the proposed hypotheses. The survey design and results are explained below.

\subsubsection{Survey respondents and procedure}

All respondents were $\mathrm{P} 2 \mathrm{P}$ accommodation hosts who operated their businesses in China. They were asked to complete an online survey, which was distributed through 27 host social media groups on WeChat. The hosts were also asked to send the survey link to their peers. We also sent the link to our known hosts. Data collection was conducted in mid-2019 and lasted a month. By the end of the survey, we had received 334 responses. Although data were collected before the current pandemic, hosts perceived the motivations and constraints scale and the theoretical framework developed in this study to be highly relevant in providing implications for helping $\mathrm{P} 2 \mathrm{P}$ accommodation recover following the pandemic.

\subsubsection{Measures}

This study identified 35 constraint items and 23 motivator items. They were measured on a 7point Likert scale $(1=$ strongly disagree, $7=$ strongly agree $)$. To measure attitudes towards the P2P accommodation business, we adapted three items from So et al. (2018). The intention to continue $\mathrm{P} 2 \mathrm{P}$ accommodation business was operationalised in three items that had been adapted from Liu and Mattila (2017). Both attitude and intention were measured on a 7-point bipolar 
scale. The final measurement items are reported in Table 1. Regarding the moderator of business scale, respondents were asked if they operated a single property or multiple properties. We asked about demographic characteristics, including gender, age, education level and annual family income. Six invited experts reviewed the questionnaire prior to the pre-test. The hosts were Chinese people who were likely to have difficulty in reading English; therefore, the questionnaire was translated into Chinese. Back-translation was then conducted to ensure that the two language versions were semantically equivalent. A pre-test was conducted among four hosts who did not indicate having any problems with the questionnaire.

Table 1. Outer loadings and the highest cross loadings of reflective constructs

\begin{tabular}{|c|c|c|c|}
\hline Label & Items & $\begin{array}{c}\text { Outer } \\
\text { Loadings }\end{array}$ & $\begin{array}{l}\text { Highest Cross- } \\
\text { loadings } \\
\text { (absolute value) }\end{array}$ \\
\hline \multicolumn{4}{|c|}{ Constraint } \\
\hline & Extra Burden (EB) & & \\
\hline EB1 & Too much effort put into maintenance & 0.867 & 0.547 \\
\hline EB2 & Too much effort put into cleaning & 0.853 & 0.555 \\
\hline EB3 & Extra expenses of cleaning & 0.819 & 0.579 \\
\hline EB4 & Extra expenses of maintenance & 0.824 & 0.633 \\
\hline EB5 & $\begin{array}{l}\text { Lack of privacy especially for those who share the same } \\
\text { accommodation with guests }\end{array}$ & 0.679 & 0.453 \\
\hline EB6 & $\begin{array}{l}\text { Safety concerns of hosts especially for those who share the } \\
\text { same accommodation with guests }\end{array}$ & 0.712 & 0.583 \\
\hline EB7 & $\begin{array}{l}\text { Lack of freedom, e.g., spending time in waiting for guests' } \\
\text { arrivals }\end{array}$ & 0.647 & 0.402 \\
\hline LC1 & $\begin{array}{l}\text { Limited Personal Capacity (LC) } \\
\text { Lack of communication skills with guests (e.g., dealing with } \\
\text { guests who do not know English) }\end{array}$ & 0.858 & 0.432 \\
\hline LC2 & Unfamiliarity with handling guests' online reviews & 0.852 & 0.424 \\
\hline LC3 & Lack of customer service skills & 0.841 & 0.407 \\
\hline $\mathrm{LC} 4$ & Unfamiliarity with the sharing economy platforms & 0.781 & 0.338 \\
\hline LC5 & $\begin{array}{l}\text { Lack of technical skills (e.g., the operation of the booking } \\
\text { system) }\end{array}$ & 0.745 & 0.348 \\
\hline
\end{tabular}




\begin{tabular}{|c|c|c|c|}
\hline LC6 & $\begin{array}{l}\text { Unfamiliarity with the legislative status of P2P accommodation } \\
\text { business } \\
\text { Weak Market Demand (WD) }\end{array}$ & 0.773 & 0.507 \\
\hline WD1 & Low occupancy rate & 0.836 & 0.420 \\
\hline WD2 & Decline in tourist arrivals & 0.728 & 0.297 \\
\hline WD3 & Seasonality & 0.710 & 0.409 \\
\hline WD4 & $\begin{array}{l}\text { Limited revenues } \\
\text { P2P Platform Constraints (PC) }\end{array}$ & 0.765 & 0.501 \\
\hline PC1 & Some platforms are not responsive to hosts' enquires & 0.714 & 0.352 \\
\hline PC2 & Frequent change of regulations of the platform & 0.783 & 0.429 \\
\hline PC3 & $\begin{array}{l}\text { Platforms favour the guests over the hosts especially when } \\
\text { there is a dispute }\end{array}$ & 0.763 & 0.530 \\
\hline PC4 & Lack of platforms' supports & 0.740 & 0.419 \\
\hline PC5 & Hard to reject bookings due to platforms regulations & 0.739 & 0.451 \\
\hline PC6 & $\begin{array}{l}\text { Inconsistent policy/requirements by different platforms } \\
\text { Guest Issues (GI) }\end{array}$ & 0.659 & 0.457 \\
\hline GI1 & $\begin{array}{l}\text { Guests' inappropriate use of hotel standard to evaluate hosts' } \\
\text { service }\end{array}$ & 0.842 & 0.563 \\
\hline GI2 & $\begin{array}{l}\text { Receive neighbours' safety concerns regarding guests as } \\
\text { strangers frequently appearing in the community }\end{array}$ & 0.667 & 0.459 \\
\hline GI3 & Guests' over expectation towards customer services & 0.823 & 0.506 \\
\hline GI4 & Emotional stress about guests' online reviews and ratings & 0.762 & 0.571 \\
\hline GI5 & $\begin{array}{l}\text { Misbehaviour of guests (e.g., not paying the full rents, make a } \\
\text { mess in the accommodation) } \\
\text { Government Regulations (GR) }\end{array}$ & 0.757 & 0.538 \\
\hline GR1 & $\begin{array}{l}\text { Intervention from the local authorities (e.g., foreign guests' } \\
\text { registration with police; Police's random checks) }\end{array}$ & 0.821 & 0.380 \\
\hline GR2 & Accreditation requirements by the local authorities & 0.721 & 0.308 \\
\hline GR3 & $\begin{array}{l}\text { Charge taxes by the government } \\
\text { Market Competition (MC) }\end{array}$ & 0.800 & 0.421 \\
\hline $\mathrm{MC} 1$ & Price War among hosts & 0.873 & 0.514 \\
\hline $\mathrm{MC} 2$ & Severe competition & 0.789 & 0.558 \\
\hline MC3 & Availability of other forms of accommodation, such as hotels & 0.742 & 0.465 \\
\hline MC4 & $\begin{array}{l}\text { Competitors' unethical practices jeopardizing the image of the } \\
\text { sharing accommodation business }\end{array}$ & 0.746 & 0.502 \\
\hline \multicolumn{4}{|c|}{$\begin{array}{ll} & \text { Motivator } \\
\end{array}$} \\
\hline $\begin{array}{l}\text { BR1 } \\
\text { BR2 } \\
\text { BR3 }\end{array}$ & $\begin{array}{l}\text { Better Interpersonal Relations (BR) } \\
\text { Learning from other cultures } \\
\text { Improving communication skills } \\
\text { Increase their social connections, e.g., making more friends }\end{array}$ & $\begin{array}{l}0.863 \\
0.842 \\
0.817\end{array}$ & $\begin{array}{l}0.419 \\
0.440 \\
0.446\end{array}$ \\
\hline
\end{tabular}




\begin{tabular}{|c|c|c|c|}
\hline \\
\hline BR4 & Becoming more outgoing & 0.792 & 0.412 \\
\hline BR5 & Improve customer service skills & 0.808 & 0.500 \\
\hline BR6 & $\begin{array}{l}\text { Allow their guests to have an authentic experience and live like } \\
\text { a local }\end{array}$ & 0.816 & 0.403 \\
\hline BR7 & Meeting new people from other cultures & 0.805 & 0.434 \\
\hline BR8 & Experiencing a certain level of "strangeness." & 0.758 & 0.424 \\
\hline & Ease of Operation (EO) & & \\
\hline EO1 & Found it easy to start & 0.972 & 0.299 \\
\hline $\mathrm{EO} 2$ & Found it easy to manage & 0.927 & 0.197 \\
\hline & Better Work-life Balance (BB) & & \\
\hline BB1 & Diversify its sources of income & 0.756 & 0.395 \\
\hline BB2 & Helping increase family income & 0.705 & 0.378 \\
\hline BB3 & $\begin{array}{l}\text { Offers more autonomy and freedom (e.g., being one's own } \\
\text { boss) }\end{array}$ & 0.862 & 0.475 \\
\hline BB4 & $\begin{array}{l}\text { Offers more flexibility (e.g., taking full control of one's time) } \\
\text { Showcasing a Trendy Character (SC) }\end{array}$ & 0.816 & 0.479 \\
\hline SC1 & Running a sharing-economy business "a cool thing" & 0.955 & 0.307 \\
\hline $\mathrm{SC} 2$ & Running a sharing-economy business "a Novel thing" & 0.960 & 0.324 \\
\hline & Settling the Cost of Living (SL) & & \\
\hline SL1 & Paying off the mortgage & 0.879 & 0.393 \\
\hline SL2 & Helping offset the cost of maintenance & 0.867 & 0.338 \\
\hline SL3 & Earning a living & 0.761 & 0.383 \\
\hline & Optimizing the Use of Resources (OR) & & \\
\hline OR1 & Use spare rooms or vacant houses as resources & 0.822 & 0.363 \\
\hline OR2 & Use spare labor force (e.g., using spare time) & 0.860 & 0.341 \\
\hline OR3 & $\begin{array}{l}\text { Use other available resources (e.g., accommodation } \\
\text { refurbishment services provided by the platforms) }\end{array}$ & 0.814 & 0.373 \\
\hline \multicolumn{4}{|c|}{ Attitude towards P2P accommodation business } \\
\hline ATT1 & Bad ... Good & 0.874 & 0.479 \\
\hline ATT2 & Unpleasant ... Pleasant & 0.850 & 0.497 \\
\hline ATT3 & Unfavorable ... Favorable & 0.878 & 0.521 \\
\hline \multicolumn{4}{|c|}{ Intention to continue P2P accommodation business } \\
\hline INT1 & Unlikely ... Likely & 0.917 & 0.575 \\
\hline INT2 & Impossible ... Possible & 0.941 & 0.501 \\
\hline INT3 & Improbable ... Probable & 0.924 & 0.520 \\
\hline
\end{tabular}




\subsubsection{Data cleaning and respondent profiles}

Among the 334 responses received in the main survey, 22 responses contained missing values and were eliminated. The remaining 312 responses were checked for outlier cases. Two cases had variables with absolute $z$-values greater than 4 , and they were removed. Therefore, the final number of responses retained for the model testing was 310 .

Regarding respondents' profiles, there were more female participants $(n=163$, proportion $=52.6 \%)$. The respondents were young in general, as almost three-fifths of the samples were under $36(n=182$, proportion $=58.7 \%)$, and they were well educated, with over $60 \%$ holding undergraduate or graduate degrees $(n=196$, proportion $=63.2 \%)$. Regarding their annual family income, the distribution was less uneven, and incomes in the range of RMB10,001 to RMB15,000 (approximately, US $\$ 1,430$ to 2,150 ) were most commonly reported ( $n=55$, proportion $=17.7 \%$.

\subsubsection{Measurement model}

To generate the factors or dimensions for the model, we conducted a principal component analysis (PCA) of the 35 constraint and 23 motivator items separately. The analyses were performed using the direct oblimin (delta $=0$ ) rotation method and an eigenvalue of 1 as the cutoff point. Seven constraint factors were generated (Kaiser-Meyer-Olkin $=0.889$; Bartlett's test of sphericity $\chi^{2}(595)=6,075.27, p=0.000$; total variance explained $\left.63.95 \%\right)$. Among the motivators, one item (i.e., believed the sharing economy would continue to grow) had a communality of less than 0.5 and was loaded to a factor that was not relevant (i.e., optimising the use of resources). Therefore, it was eliminated, and PCA was performed again on the remaining 
22 items. The analysis generated six motivator factors (Kaiser-Meyer-Olkin $=0.837$; Bartlett's test of sphericity $\chi^{2}(231)=4,146.83, p=0.000$; total variance explained $\left.73.05 \%\right)$. In the final models, all absolute values of factor loadings were greater than 0.4 , and communalities were above 0.5. The factor labels are shown in Table 1 .

The measurement model was further examined by applying Partial Least Square Structural Equation Modelling (PLS-SEM). The sample size was deemed adequate after taking in account the largest number of structural paths pointing towards a construct, power analysis (Hair et al. 2017) and inverse square root method (Kock and Hadaya, 2018). Given the latent dimensions of the constraints and motivators, a hierarchical component model (HCM) needed to be formed. This was an exploratory study; thus, the nature of the measurement model of constraints and motivators was uncertain (i.e., reflective or formative). We empirically examined it using confirmatory tetrad analysis (CTA) in the PLS-SEM. As Becker et al. (2012) suggested, a twostage approach was adopted. First, the latent scores of the dimensions of the constraints and motivators were generated. CTA-PLS requires two criteria, which are as follows: (1) at least some indicators (i.e., dimensions) are significantly correlated and (2) more than three indicators per measurement model. The constraint dimensions were all significantly correlated with each other $(p<0.05)$, while 14 out of 16 correlations among the motivator dimensions were statistically significant. Therefore, the first criterion was met. Both the categories of constraints and motivators had more than three dimensions, and thus, the second criterion was met. Both constraints and motivators had at least one tetrad with a bias-corrected and Bonferroni-adjusted confidence interval not including zero, indicating that their measurement models should be formative. As such, reflective-formative HCMs of the constraints and motivators were formed and tested (see Figure 2). 


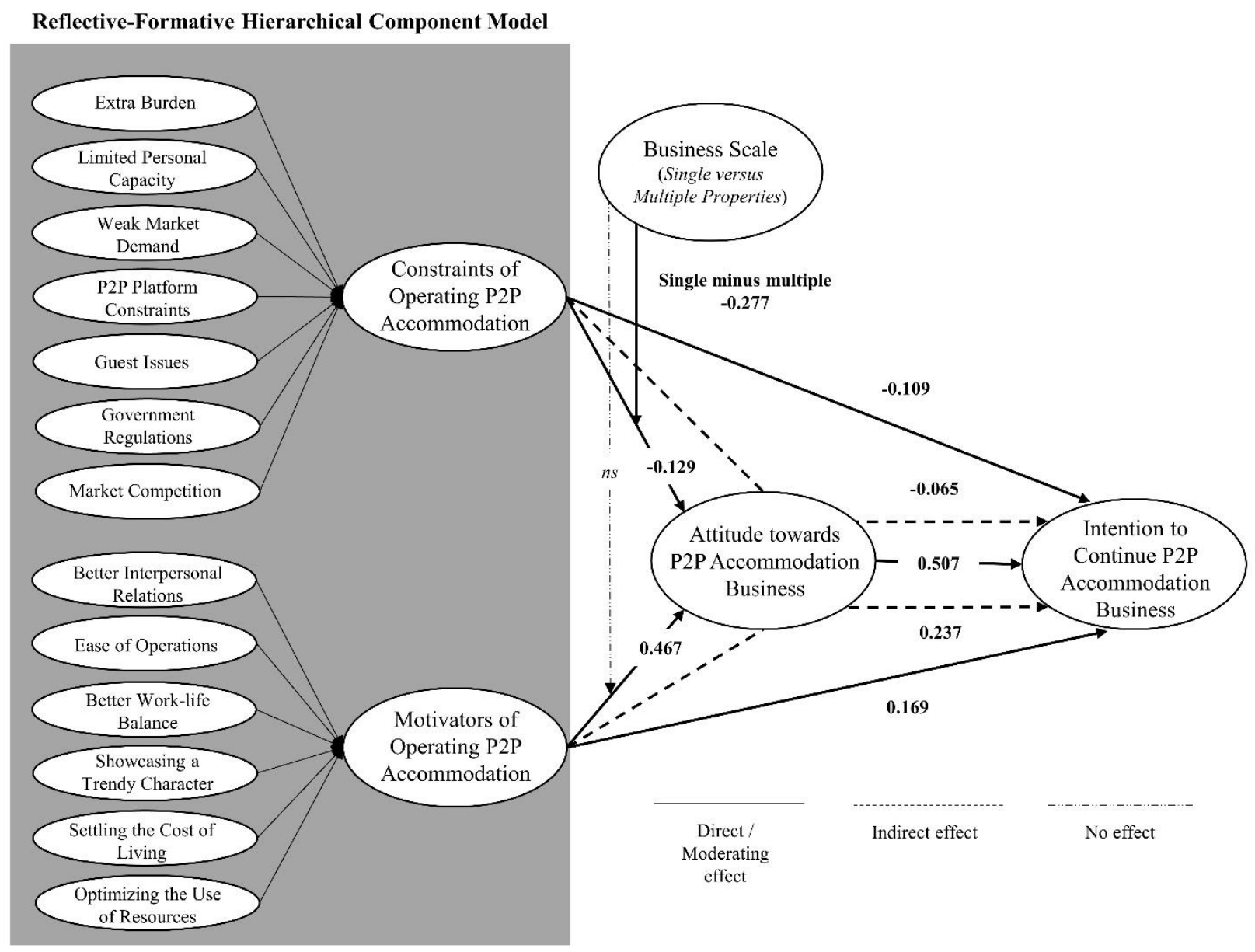

Figure 2. Model estimation results

(Note. Statistically significant results are bolded; $n s$ denotes non-significant results).

The use of bootstrapping estimation in the PLS-SEM ruled out the concern of data normality. First, the adequacy of the measurement model was assessed. We evaluated the internal consistency and validity of the measures based on multiple criteria. Internal consistency was demonstrated, as all composite reliability values were greater than 0.7 (see Table 2 ). The outer loadings were relevant, as they were above 0.4 . The elimination of items with outer loadings below 0.7 did not lead to an increase in composite reliability, and, thus, they were retained. Convergent validity existed because the average variance extracted (AVE) values were greater than 0.5. Discriminant validity also existed because of three results: (1) the outer loadings 
of the items were greater than their cross-loadings (see Table 1); (2) the AVE values exceeded square correlations with other constructs (see Table 2); (3) the Heterotrait-Monotrait Ratio (HTMT) values were less than 0.9 (the largest value was 0.793 ), while the HTMT inference criterion of the bias-corrected confidence intervals did not include 1 .

\subsubsection{Common method bias}

To examine if the common method bias existed, we conducted Harman's Single-Factor Test. A PCA of all items (without rotation) resulted in more than one factor, and the first factor explained $20.17 \%$ of the variance (far below 50\%). The results indicated that this bias did not exist. To further validate the results, we adopted the unmeasured latent market construct method. The conclusion remained, as (1) a few method factor loadings were statistically significant, (2) the substantive variances of items exceeded their method variances, and (3) the ratio of average substantive variance to average method variance (233:1) was large.

\subsubsection{Structural model}

The adequacy of our structural model was reflected in the non-existence of multicollinearity issues (all variance inflation factors were less than 5) and satisfactory predictive accuracy (the blindfolding test reported $\mathrm{Q}^{2}$ values above zero).

The results of the hypothesis tests about the direct and indirect effects are shown in Figure 2. All hypotheses were supported. Constraints were negatively associated with attitude 
$\left(\mathrm{H} 1\right.$ : coefficient $\left.=-0.129, p<0.05, f^{2}=0.018\right)$, while motivators were positively associated with attitude $\left(\mathrm{H} 3\right.$ : coefficient $\left.=0.467, p<0.001, f^{2}=0.241\right)$. Attitude was positively related to intention $\left(\right.$ Coefficient $\left.=0.507, p<0.001, f^{2}=0.321\right)$. The constraint-intention relationship was significant $($ coefficient $=-0.109, p<0.05)$, and attitude partially mediated the relationship $(\mathrm{H} 2$ : coefficient $=-0.065, p<0.05$, Variance accounted for $=0.374)$. Similarly, the motivatorintention relationship was significant (coefficient $=0.169, \mathrm{p}<0.05)$, and attitude partially mediated the relationship (H4: coefficient $=0.237, p<0.001$, Variance accounted for $=0.584)$. The coefficients indicate that motivators have stronger effects on attitude and intention than constraints do. The $R^{2}$ values of attitude and intention are $0.195(p<0.001)$ and $0.355(p<$ 0.001), respectively.

\subsubsection{The moderating effect of business scale}

Business scale was a dichotomous variable (single versus multiple properties). Thus, Hypotheses $5 \mathrm{a}$ and $5 \mathrm{~b}$ were examined using multi-group analysis, which requires the sample size of the bigger group to be less than twice the size of the smaller group (Hair et al. 2018). This criterion was met as there were 178 cases recorded of single-property businesses, which was less than twice the 121 cases of multiple-property businesses (i.e., 242). The analysis also requires the establishment of configural invariance and partial or full measurement invariance.

Configural invariance was demonstrated, as indicators, data coding and algorithm settings were the same for both groups. Measurement invariance was examined using a measurement invariance of composite model (MICOM). According to the MICOM Step 2 results, correlation $c$ values exceeded those of the $1 \%$ quantile of the empirical distribution of $c_{\mathrm{u}}$. Therefore, the compositional invariance of the measurement was established. Regarding the MICOM Step 3 
results, the mean values were unequal for limited personal capacity $(p=0.025)$, market competition $(p=0.012)$ and ease of operation $(p=0.037)$. For variances, all values were equal. Hence, partial measurement invariance was confirmed, and multi-group analysis was deemed adequate (Hair et al., 2018).

The results of the moderating effects of business scale on the constraint-attitude and motivator-attitude relationships are reported in Table 3. The permutation test, PLS-MGA, parametric test and Welch-Satterthwaite $t$-test converged on the same conclusion that the moderating effect exists in the constraint-attitude link (all $p$-values $<0.05$ ) but not in the motivator-attitude link (all $p$-values $>0.05$ ). By separately conducting structural modelling analyses for single-property and multiple-property businesses, we found that the constraintattitude link was significantly negative only for the single-property group $($ coefficient $=-0.241, p$ $<0.05)$ and not for the multiple-property group (coefficient $=0.036, p>0.05)$. The motivatorattitude link was positively significant for both groups $(p<0.05$; see Table 3$)$. Thus, H5 was supported.

<Insert Table 3 here>

\subsection{Study 2: Methods and findings}

The goal of the supplementary qualitative study (Study 2) was to provide interpretive evidence of the relationships among constraint, motivation, attitude, business scale and intention to continue one's P2P accommodation business in China. After the survey, we interviewed 20 hosts from different backgrounds to gather more detailed information. The duration of the interviews ranged from 25 to 45 minutes, with an average of approximately 30 minutes. The interview was audio recorded with the consent of the participants. The interviews ended when no new substantive 
information emerged. Two of the authors conducted the interviews and took notes and then adopted a thematic analysis to organise and understand the data (Boyatzis, 1998).

First, the results revealed that the respondents jointly evaluated the negative impacts of constraints and the merits of motivators in the formation of their attitude and intention to continue their P2P accommodation businesses. Anna (63, a retired doctor, single property) noted, 'I have to put in a lot of effort. I do not have to rely on this tiny profit for a living. Cleaning, replying to customers' inquiries and even worrying that they may commit some crime in my property. I like meeting new people, but it is not fun now.' Likewise, Stacey (32, in marketing, single property) said, 'I shared the property with my guests. I meet a lot of people, but as a woman, I am always concerned about my safety. Some minor incidents of sexual harassment have happened.' The perceived constraints outweighed the novelty and desire of interpersonal relations, leading these respondents to an intention to quit.

In line with the survey results concerning the moderating role of business scale, the findings of Study 2 show that the owners of multiple properties were less affected by constraints. Joyce (42, business owner, multiple properties), who owned many high-end properties in Shanghai, expressed that 'our well-designed villa is less likely to have many constraints, [un]like those who use their own home to run $\mathrm{P} 2 \mathrm{P}$ accommodation. Our properties will bring the right clients, who want to experience natural beauty. Sometimes, we receive clothing designers' requests on the platforms. They use our villa to take photos. It is a really exciting new opportunity for us'.

All of the hosts listed their properties on various platforms, but the majority expressed that they had had a good experience with the local Chinese platforms and a relatively negative experience with Airbnb. Tom (50, engineer, single property) explained, 'It is extremely hard to 
contact customer services on Airbnb. They want a commission and to regulate us without delivering much. Tujia is great. Their manager teaches me how to do things and even replies to my customers. You can also transfer these features to Xiaozhu easily, but not to Airbnb.' Many studies focusing on Chinese culture have shown that Chinese people emphasise interpersonal contact (e.g., Zhang et al., 2019). The extra interpersonal services provided by local platforms have made Chinese hosts more likely to choose them. Criticisms of Airbnb have increased over its failure to adapt to Chinese culture and its limited selection of Chinese hosts compared with local platforms (Beijing News, 2020). However, some younger Chinese hosts believe that 'Airbnb is an internationally recognised brand. They bring better quality people than the local platforms do. They are fun and innovative to live with' (Lucy, 25, single property). Nevertheless, the perceived special interpersonal relations might be a unique selling point, differentiating the local Chinese platforms from Airbnb.

\section{Discussion and conclusions}

\subsection{Conclusions}

The sharing economy has become an important and popular research topic (Heo, 2016). The findings of the present study contribute to the further development of a theoretical understanding of the sharing economy. Using a mixed-methods approach with two studies, this paper captures a comprehensive set of motivation and constraint factors facing hosts and builds a theoretical framework to validate the predictive power of these factors on hosts' attitudinal and behavioural 
responses. Qualitative data provide several in-depth explanations for the key findings generated from the questionnaire survey. The paper contributes to the formation of a holistic framework for analysing the motivations and constraints affecting continuity in a key sector of the sharing economy, $\mathrm{P} 2 \mathrm{P}$ accommodation. Although the factors that encourage or deter guests from staying in P2P accommodation have been well examined in the literature (e.g., So et al., 2018; Tussyadiah, 2015), the full set of motivation and constraint factors that affect existing hosts' intention to continue in the business remains unexplored. The literature on the motivator and constraint factors of hosts has emphasised their influence on the decision to join the business, and have paid more attention to the growth of the sharing economy. The emerging issues that may deter the sustainability of the business have received little attention. This paper contributes by examining the power of motivations and constraints in determining hosts' continuance intention. The influencers on existing hosts to continue to run their businesses are vital to the sustainable development of the sharing economy.

\subsection{Theoretical implications}

This research enriches the discussion on the sharing economy through (a) testing factors captured in previous studies and (b) uncovering additional key drivers and deterrents. The findings of our semi-structured in-depth interviews revealed various themes of constraint and motivation. The additional qualitative findings provided interpretive evidence to support and explain the survey results. The hosts' perceived constraints included themes that have been identified in previous research, such as guest issues, government regulations and market competition (e.g., Alraeeini et 
al., 2019; Malazizi et al., 2018). The findings on P2P platforms constraints, including the difficulty of rejecting a booking due to platform regulations, and inconsistency in the policy/requirements of different platforms, align with those of Farmaki (2019), who noticed that Airbnb's inconsistent regulations and favouring of guests presented challenges to hosts seeking to reject bookings. Our results uncovered new items, such as the need to put much effort into maintenance and cleaning.

Among the motivators, better interpersonal relations, settling the cost of living, optimising the use of resources and ease of operation have been reported in the literature (e.g., Farmaki and Stergiou, 2019; Karlsson and Dolnicar, 2016). The result of offering more autonomy, freedom and flexibility is consistent with Benoit et al. (2017). Jung et al. (2016) found that having a 'human relationship' becomes a key shared asset of $\mathrm{P} 2 \mathrm{P}$ accommodation, but making a profit remains important. Our findings uncovered motivators that have not been discussed in the literature, including showcasing one's trendy character, such as feeling it was 'a cool thing' or 'a novel thing' to run a sharing-economy business, and being one's own boss.

Most existing studies have investigated P2P accommodation hosts operating on the Airbnb platform in the West, such as in Northern Cyprus (Malazizi et al., 2018), the United States (Ert and Fleischer, 2019) and Europe (Farmaki and Stergiou, 2019). This paper is among the few that explore hosts operating P2P accommodation on global and local platforms in Asian countries. Thus, it generates several new ideas about motivations and constraints; the perception that it is 'a cool/novel thing' to run a sharing-economy business appears to be one of the most important motivators in this context. Previous studies have reported that sharing and interaction are the key drivers of joy (Karlsson and Dolnicar, 2016). Complementing this aspect of the literature, our study found that considering the operation of P2P accommodation to be 'a cool/novel thing' 
made Chinese hosts feel good. Our findings also reveal that hosts face new P2P platform constraints, including a lack of technical support and non-responsiveness to hosts' inquiries. These issues may be due to a lack of professional workers on platforms or hosts' unfamiliarity with the platforms and relevant regulations. Chinese hosts also felt that having to put too much effort into maintenance was a severe constraint. This finding differs from Mahadevan (2019), who found that opportunity costs, including time and effort investment in maintenance, was not significantly associated with the intention to become a host based on a survey among Australians. This might be because, unlike Western hosts, most Chinese are not used to engaging in accommodation maintenance by themselves.

The paper enriches the literature by developing a scale to measure the motivators and constraints of operating $\mathrm{P} 2 \mathrm{P}$ accommodation. The predictive power and validity of motivators and constraints were demonstrated in the relationships with attitude and behavioural intention. The advantage of this empirical examination is that it took the influence of both motivation and constraint factors into account on determining outcome variables. The results indicate that constraints lower the intention to continue one's business because of an unfavourable attitude, whereas motivators heighten the intention because of a favourable attitude.

The simultaneous examination of motivators and constraints enabled the comparison of their effects on attitude and intention. We found that in general, motivators had a greater effect on attitude and intention than did constraints. Motivations play a more important role than do constraints in influencing hosts' attitudes towards P2P sharing accommodation. The findings are not surprising if the moderating effect of business scale is considered. The positive effect of motivators on attitude is positive and robust against business scale, whereas the negative effect of constraints on attitude only exists for single-property hosts. In line with the size-survival 
relationship (Bercovitz and Mitchell, 2007), we found that constraints have a greater impact on small businesses (i.e., single properties) owing to their insufficient resources to address the problems arising from the constraints. Therefore, single-property hosts hold a greater negative attitude towards operating a $\mathrm{P} 2 \mathrm{P}$ accommodation. The motivator effect is not contingent on business scale because motivation is internalised to the host. This internalised trait has low relevancy with the external factor of business scale. Their interaction did not influence attitude. The findings of the moderating effect add knowledge to the literature by showing the asymmetrical effects of constraints and motivators on their consequences. Future research should examine the boundary situation qualifying the constraint and motivator effects.

\subsection{Practical implications}

This study identifies several constraints on operating P2P accommodation. The major constraints include platforms favouring guests over hosts, especially in disputes; inconsistent policy/requirements by different platforms; and the difficulty of rejecting bookings due to platforms' regulations. Platforms should develop clear, transparent and consistent regulations to clarify the duties and responsibilities of hosts and guests. In terms of guest issues, hosts highlighted the emotional stress caused by guests' online reviews and ratings, as they are highly concerned about guests' inappropriate use of hotel standards to evaluate hosts' accommodation and customer service. It is advised that platforms include information on their websites to explain the differences between sharing accommodation and hotels, which may help to adjust guests' expectations. Platforms can help hosts cope with the emotional stress caused by online reviews. They can facilitate hosts' sharing of their views and emotions with other hosts on social media, such as in a WeChat group or Facebook page built for hosts. Furthermore, our results 
imply that hosts, especially new entrants, are facing limited personal capacity constraints. Working with the relevant industry associations, platforms could provide self-learning packages and training to enable hosts to familiarise themselves with the legislative status of the P2P accommodation business and improve their communication skills with guests. Platforms could also work with third parties to offer services, such as maintenance and cleaning, to reduce hosts' burden. Finally, there should be measures to reinforce the motivations recognised by hosts. For example, platforms could provide opportunities for offline interactions between guests and hosts, especially for those who value interpersonal relations as a motivator. Brands that showcase the trendy characterisations of the sharing accommodation business could be designed to attract new hosts.

The results have two types of policy implication for government departments. First, government regulations, such as the intervention and accreditation requirements of the local authorities and the charging of taxes, pose significant constraints for existing hosts. $\mathrm{P} 2 \mathrm{P}$ accommodation hosts are suffering from an increase in expenses and dramatic decrease in revenues due to COVID-19 (Dolnicar and Zare, 2020). Unclear government regulations seem to be an underlying constraint on sharing accommodation, especially in the context of this crisis. Therefore, it is crucial to design new regulatory measures (Dolnicar, 2019) to standardise rules for this novel market and offer support for its sustainable development. Second, the other major concerns for hosts are weak market demand and stiff market competition. Similar to traditional tourism and hospitality businesses, the sharing accommodation industry is sensitive to the external market environment. Tourism bureaus and hospitality associations should incorporate this business into their marketing strategies and promote it with unique and positive images. 
Regulations over price wars among hosts and competitors' unethical practices should also be considered.

This paper also has novel insights for existing and future hosts. They should measure prospective gains against costs according to the holistic framework developed in this paper before deciding to join, continue or exit the P2P sharing business. Hosts need to be fully aware of the constraints and alert to potential problems, such as regulations, guest issues and seasonality, so that they can prepare the corresponding solutions. Hosts should carefully consider the recommendations for addressing constraints, especially if they operate a single property, given the moderating effect of business scale.

\subsection{Limitations and future research}

The implications of this study should be considered in light of several limitations. First, despite our efforts to recruit diverse participants, the population of Chinese hosts was unknown. We might have missed hosts who were resistant to taking part in the study. Future studies could try to extend the sample to reach hosts in other Asian countries, where local platforms are also popular. Second, the P2P platform constraint reflected respondents' generic experiences with various online platforms. The variances aroused from evaluations based on global or local platforms were unknown. Future research is recommended to measure this constraint factor by asking the respondents to base their evaluation on a particular platform or the one that they most recently used. Third, the COVID-19 pandemic is likely to have altered hosts' perceptions on motivations and constraints that were not captured in this research, which was conducted before the pandemic. However, the measurement scale and model developed in this paper can provide a useful framework for future research to explore the motivators and constraints caused by the 
pandemic. This research examined hosts operating sharing accommodations in China. A review of the literature showed that most studies have focused on hosts in Western countries; thus, the findings of this paper are both general and unique constraints and motivations. Future research could examine the similarities and differences in the attitudes and behavioural intentions of hosts in Western and Eastern countries.

\section{References}

Ajzen, I. (1991), "The theory of planned behavior", Organizational Behavior and Human Decision Processes, Vol. 50 No. 2, pp.79-211.

Alrawadieh, Z. and Alrawadieh, Z. (2018), "Exploring entrepreneurship in the sharing accommodation sector: Empirical evidence from a developing country", Tourism Management Perspectives, Vol. 28, pp.179-188.

Alraeeini, M., Zhong, Q. and Antarciuc, E. (2019), “Analysing drivers and barriers of accommodation sharing in Dubai using the Grey-DEMATEL approach”, Sustainability, Vol. 11 No. 20, 5645.

Amaro, S., Andreu, L. and Huang, S. (2019), "Millenials' intentions to book on Airbnb", Current Issues in Tourism, Vol. 22 No. 18, pp.2284-2298.

Alstete, J.W. (2008), “Aspects of entrepreneurial success”, Journal of Small Business and Enterprise Development, Vol. 15, No. 3, pp. 584-594.

Becker, J.M., Klein. K., and Wetzels, M. (2012), "Hierarchical Latent Variable Models in PLSSEM: Guidelines for using reflective-formative type models", Long Range Planning, Vol. 45 No. 5, pp.359-394. 
Beijing News (2020), "Airbnb and localization in China", available at: http://www.bjnews.com.cn/feature/2020/01/15/674545.html (Chinese) (accessed 20 August 2020)

Benoit, S., Baker, T.L., Bolton, R.N., Gruber, T., and Kandampully, J. (2017), “A triadic framework for collaborative consumption (CC): Motives, activities and resources \& capabilities of actors", Journal of Business Research, Vol. 79, pp.219-227.

Bercovitz J. and Mitchell, W. (2007), "When is more better? The impact of business scale and scope on long-term business survival, while controlling for profitablity", Strategic Management Journal, Vol. 28, pp.61-79.

Böcker, L. and Meelen, T. (2017), "Sharing for people, planet or profit? Analysing motivations for intended sharing economy participation", Environmental Innovation and Societal Transitions, Vol. 23, pp.28-39.

Boyatzis, R.E. (1998). Transforming Qualitative Information: Thematic Analysis and Code Development. Sage Publications, Thousand Oaks, CA.

Cheng, M. and Edwards, D. (2019), “A comparative automated content analysis approach on the review of the sharing economy discourse in tourism and hospitality", Current Issues in Tourism, Vol. 22 No. 1, pp.35-49.

Churchill, G.A. (1979), "A paradigm for developing better measures of marketing constructs”, Journal of Marketing Research, Vol. 16 No. 1, pp.64-73.

Creswell, J.W., Plano Clark, V. L., Gutmann, M.L. and Hanson, W. E. (2003), “Advanced mixed methods research designs", Tashakkori, A., Teddlie, C. (Ed.s.), Handbook of Mixed Methods in Social and Behavioral Research, Sage Publications, Thousand Oaks, CA, pp.209-240. 
Dolnicar, S. (2019). “A review of research into paid online peer-to-peer accommodation:

Launching the Annals of Tourism Research curated collection on peer-to-peer accommodation”, Annals of Tourism Research, Vol. 75, pp.248-264.

Dolnicar, S. and Talebi, H. (2020), "Does hosting on Airbnb offer hosts vacation-like benefits? Proposing a reconceptualization of peer-to-peer accommodation", Journal of Hospitality and Tourism Management, Vol. 43, pp.111-119.

Dolnicar, S., and Zare, S. (2020), "COVID19 and Airbnb-disrupting the disruptor", Annals of Tourism Research, Vol. 83, 102961.

Ert, E. and Fleischer, A. (2019), "The evolution of trust in Airbnb: A case of home rental", Annals of Tourism Research, Vol. 75, pp.279-287.

Farmaki, A. (2019), "Women in Airbnb: A neglected perspective", Current Issues in Tourism, https://doi.org/10.1080/13683500.2019.1674257.

Farmakia, A. and Stergioub, D.P. (2019), "Escaping loneliness through Airbnb host-guest interactions", Tourism Management, Vol. 74, pp. 331-333.

Guttentag, D. (2015), “Airbnb: Disruptive innovation and the rise of an informal tourism accommodation sector", Current Issues in Tourism, Vol. 18, pp.1192-1217.

Hair, J.F.J., Sarstedt, M., Ringle, C.M. and Gudergan, S.P. (2018), Advanced Issues in Partial Least Squares Structural Equation Modeling. Sage Publications, Los Angeles, CA. Hair, J.F., Hult, G.T.M., Ringle, C.M. and Sarstedt, M. (2017), A Primer on Partial Least Squares Structural Equation Modeling (PLS-SEM) (2nd ed.). Sage Publications, Los Angeles, CA. 
Halkos, G.E. and Tzeremes, N.G. (2007), "Productivity efficiency and firm size: An empirical analysis of foreign owned companies”, International Business Review, Vol. 16 No. 6, pp.713-731.

Hamari, J., Sjoklint, M. and Ukkonen, A. (2015), “The sharing economy: Why people participate in collaborative consumption", Journal of the Association for Information Science and Technology, Vol. 67 No. 9, pp.2047-2059.

Heo, Y. (2016), "Sharing economy and prospects in tourism research", Annals of Tourism Research, Vol. 58, pp.166-170.

Huang, S. and Hsu, C.H.C. (2009), "Effects of travel motivation, past experience, perceived constraint, and attitude on revisit intention”, Journal of Travel Research, Vol. 48, No. 1, pp.29-44.

Jung, J., Yoon, S., Kim, S., Park, S., Lee, K.P. and Lee, U. (2016), “Social or financial goals? Comparative analysis of user behaviors in Couchsurfing and Airbnb", The 2016 CHI Conference, San Jose, CA.

Karlsson, L. and Dolnicar, S. (2016), “Someone's been sleeping in my bed”, Annals of Tourism Research, Vol. 58, pp.159-162.

Karlsson, L., Kemperman, A. and Dolnicar, S. (2017), "May I sleep in your bed? Getting permission to book", Annals of Tourism Research, Vol. 62, pp.1-12.

Kaul, A. (2012), “Technology and corporate scope: Firm and rival innovation as antecedents of corporate transactions", Strategic Management Journal, Vol. 33 No. 4, pp.347-367.

Kock, N., and Hadaya, P. (2018), "Minimum sample size estimation in PLS-SEM: The inverse square root and gamma-exponential methods", Information Systems Journal, Vol. 28 No. 1, pp.227-261. 
Liu, S.Q., and Mattila, A.S. (2017), “Airbnb: Online targeted advertising, sense of power, and consumer decisions", International Journal of Hospitality Management, Vol. 60, pp.3341.

Mahadevan, R. (2019), “To be or not to be a host in the peer-to-peer accommodation sector", International Journal of Hospitality Management, Vol. 81, pp.159-168.

Malazizi, N., Alipour, H. and Olya, H. (2018), "Risk perceptions of Airbnb hosts: Evidence from a Mediterranean Island”, Sustainability, Vol. 10 No. 5, 1349.

Moon, H., Miao, L., Hanks, L. and Linee, N.D. (2019), "Peer-to-peer interactions: Perspectives of Airbnb guests and hosts", International Journal of Hospitality Management, Vol. 77, pp.405-414.

OECD. (2016), Policies for the tourism sharing economy, OECD Publishing, Paris.

Prayag, G. and Ozanne, L.K. (2018), “A systematic review of peer-to-peer (P2P) accommodation sharing research from 2010 to 2016: Progress and prospects from the multi-level perspective”, Journal of Hospitality Marketing \& Management, Vol. 27 No. 6, pp.649678.

Pritchard, M.P., Funk, D.C. and Alexandris, K. (2009), "Barriers to repeat patronage: The impact of spectator constraints", European Journal of Marketing, Vol. 43 No. 1/2, pp.169-187.

PwC. (2015), "The sharing economy", available at:

http://www.pwc.com/us/en/industry/entertainment-media/publications/consumerintelligenceseries/ assets/pwc-cis-sharing-economy.pdf (accessed February 20, 2020).

So, K.K.F., Oh, H. and Min, S. (2018), "Motivations and constraints of Airbnb consumers: Findings from a mixed-methods approach”, Tourism Management, Vol. 67, pp.224-236. 
Stors, N., \& Kagermeier, A. (2017), “Airbnb-hosts as players in new urban tourism: motivation in participating from the supply-side perspective", Geographische Zeitschrift, Vol. 105 No. 3-4, pp.190-224.

Tham, A. (2016), "When Harry met Sally: Different approaches towards Uber and AirBnB—An Australian and Singapore perspective", Information Technology \& Tourism, Vol. 16 No. 4, pp.393-412.

Tussyadiah, I.P. (2015), “An exploratory study on drivers and deterrents of collaborative consumption in travel", Tussyadiah I., Inversini A. (Ed.s.), Information and Communication Technologies in Tourism 2015, Springer, Cham, pp.817-830.

Tyagi, R.K. (2001), “Why do suppliers charge larger buyers lower prices?” The Journal of Industrial Economics, Vol. 49 No. 1, pp.45-61.

Wang, Y., Asaad, Y. and Filieri, R. (2019), "What makes hosts trust Airbnb? Antecedents of hosts' trust toward Airbnb and its impact on continuance intention", Journal of Travel Research, Vol. 5, pp.1-18.

Xie, K.L., Mao, Z., Okumus, F. and Altinay, L. (2017), “The impacts of quality and quantity attributes of Airbnb hosts on listing performance", International Journal of Contemporary Hospitality Management, Vol. 29, pp.2240-2260.

Zaridis, A., Vlachos, I. and Bourlakis, M. (2020), "SMEs strategy and scale constraints impact on agri-food supply chain collaboration and firm performance", Production Planning \& Control, DOI:10.1080/09537287.2020.1796136.

Zhang, C.X., Pearce, P. and Chen, G. (2019), "Not losing our collective face: Social identity and Chinese tourists' reflections on uncivilised behaviour", Tourism Management, Vol. 73, pp.71-82. 
